\title{
The Sustainable Development of Rural Areas
}

\author{
Maria Colucci, Annunziata Palermo, Mauro Francini \\ Department of Civil Engineering, University of Calabria, 87036 Rende (CS), Italy
}

\begin{abstract}
Up to now, a large part of the debate and the initiatives involving rural areas have still tended to concentrate on activities orientated to markets (qualification of the productions, valorisation of the system of services to tourism, interventions on the valorisation of cultural resources), leaving the support actions regarding social capital and human resources in the background. The renewed centrality of the rural nature of local development directions needs careful reflection on the significance of the support actions and policies of these areas. The material resources (the products, services, high quality manufactured goods) and immaterial resources (local culture, traditions, lifestyles) present in rural areas are an integral part of the values around which the development actions of these territories, and not only these, must absolutely revolve. For this reason, rural area support policies must provide for, besides the support of productive activities, interventions on the available social capital, favouring its continuity and renewal. Investment in human resources assumes, therefore, renewed significance for the promotion of the rural character, laying the bases, for a re-qualification action, which has now become indispensable.
\end{abstract}

Keywords-rural areas, local development, social dynamics.

\section{INTRODUCTION}

To date, much of the debate and initiatives affecting the rural areas still tend to focus on business-oriented markets (qualifying production, strengthening the system of services to tourism, development of cultural resources), leaving in the background actions supporting the social capital and human resources. In the reflection of the European Community, however, rural areas are seen as an opportunity for the requalification of the economic development as a whole and for raising the welfare of the European population, a welfare more often compromised by negative externalities, environmental and social, related to the concentration of development poles in territorial portions increasingly restricted.

Within a Community framework in rapid evolution, it is therefore necessary to refer to the value of rural areas, both for the promotion of the local economy, both in terms of increased levels of well-being and quality of life [1].

In Italy, most of the rural areas share similar challenges, such as the difficulty in the development of local resources, the exodus of young people, the low rate of entrepreneurship, the dissatisfaction of the economic and social needs of rural populations, and the lack of an effective coordination between the public administration and local actors, in order to preserve and enhance the territorial richness.

In this context, in order to achieve a sustainable and competitive socio-economic development, it is necessary to implement specific strategies, methodologies and tools [2].

\section{THE SOCIAL DIMENSION OF SUSTAINABLE DEVELOPMENT}

Over the years there has been a shift from an economic vision of development, which measured levels only through the values of income growth and gross domestic product, to a new vision in which development becomes social, connected to a set of collective variables, such as education, health, civil and political rights, protection of minorities, all essential in the process now acquired of the sustainability. The concept of sustainable development is, therefore, undoubtedly related to the problems inherent in economic progress, but also inextricably linked to social dynamics. In this context, migration processes were essential and decisive in the history of our company, and as a destructive phenomenon, in reference to the starting areas, and as a factor of transformation of the areas of new settlement. The sociological analysis conducted in recent years have highlighted the connection between immigration, economic and productive reorganization, transformation of urban and rural areas, and thus development [3].

In this regard, it should be remembered that social policies in our country have long been the subject of a profound redefinition. It is, in fact, actually a slow transition from purely assicurative and reparative policies to patterns of local development processes that can directly promote social inclusion. Underlying this shift there are two major acquisitions.

First is growing awareness that new risk profiles of marginalization and exclusion, as well as new social demands of the recent transformations, cannot find satisfaction in the established systems of social policies, based on the assicurative model and on solidarity national based. In particular, in rural areas this bottleneck, which has produced new forms of insecurity and exclusion, is added to the chronic difficulties of providing health and social services because of the dispersion of settlements. These two gaps become an obstacle to development because they reduce the attractiveness of these areas compared to urban centers.

Therefore coexist, on the one hand, a new and growing demand of rurality, fueled by urban residents sensitive to the protection of ecological values and 
historical and cultural heritage and, on the other hand, an erosion of social protection networks. This results in a highly contradictory picture of the potential development of rural areas.

The second acquisition is subsequent to the first.

A revival of social policies can only pass through the ability to re-invent a link between social protection and economic and productive development. It is necessary to assume as the objective of social policies not only the socialization of the individual risks, but also the removal of obstacles to economic development. Many of these obstacles have their origin in social problems, often with clear territorial impact: the growing demographic imbalances, the depletion of settlements in rural areas more inland, the isolation, the poverty and the social exclusion.

The reconstitution of a link between social protection and economic and productive development urges, therefore, a rethinking of the processes of government and of the same sectoralisation where are relegated social policies. It is, in essence, to broaden the spectrum of social policies until encompass policies with high territorial value, such as housing, those active labor, the urban planning, as well as those concerning the development of rural systems [4].

\section{ACTIONS AND POLICIES SUPPORTING RURAL AREAS}

The renewed centrality of rurality in the paths of local development requires careful reflection on the meanings of actions and policies to support these areas. Material resources (products, services, valuable artifacts) and intangible resources (local culture, traditions, lifestyles) present in rural areas are an integral part of the values on which absolutely have to pivot the development actions for these territories, and beyond.

For this reason, policies in support of rural areas must be provided, plus support for productive activities, interventions on available social capital, favoring continuity and renewal. The investment on human resources assumes, then, a renewed significance for the promotion of rurality, laying the basis for actions of regeneration, now become indispensable [5].

In particular, the development of social protection networks acquires direct meaning to those territories and, at the same time, may be flying for further development and increased levels of welfare, as the field of personal services for a long time was considered a possible employment basin.

Unlike other areas, in rural areas, as well as the organization and delivery of services by public or private, thickening of safety nets, and therefore also the ability to generate employment, for example, can be born in the same farms, specifically specialized and oriented.

From this point of view, the issue of multifunctionality in agriculture, as well as forming the point of reflection for a stronger integration of primary economy and society, is a means by which to ensure innovative forms of income generation and, also, make actual the networks of self- protection and mutual aid that have always been present in the culture and lifestyles of rural areas [6].

Exploring the feasibility of a real integration between production of goods and services - also in the social field by agricultural activities, are assumed service models focused on the development of agricultural resources present on the territory for social purposes. It is, therefore, possible to assume and consolidate a network of services that allows to focus on high levels of public-private integration where, farms, for some functions, can play an active role towards the local companies, but also users from other areas.

A thickening of the protection networks and their link with agricultural activities would have the advantage of offering a strongly renewed and positive values of rurality, increasing in local communities a sense of belonging, self-image and improving conditions of life. At the same time, transferring this image outside of the local communities, would be increased elements of specificity and differentiation of these territories, increasing the visibility and the interest in the eyes of visitors and potential new residents [7].

\section{REFERENCES}

[1] Leopardi I., Sassi M., Il modello di sviluppo rurale definito dall'UE dalla teoria all'attuazione: una sfida ancora aperta. Quaderno di ricerca n. 6, Pavia: Copyland, 2004.

[2] Lucatelli S., Monteleone A., Valutazione e sviluppo delle aree rurali: un approccio integrato nella valutazione delle politiche di sviluppo, Collana Materiali UVAL, 2005.

[3] Francini M., (Eds), Modelli di sviluppo di aree interne ad alta ruralità, Cosenza: Centro Editoriale e Librario - Università della Calabria, 2006.

[4] Pascucci S., Periurban agriculture and rural development strategies, Collana Working Paper, 2007.

[5] Regione Calabria, Documento Strategico Regionale sullo sviluppo rurale. Linee strategiche, metodi e tempi, 2007.

[6] Regione Calabria, Unione Europea, Ministero delle Politiche agricole, alimentari e forestali, Programma di Sviluppo Rurale della Regione Calabria 2007-2013 (Regolamento (CE) n. 1698/2005).

[7] Balestrieri G., Il turismo rurale nello sviluppo territoriale integrato della Toscana, Firenze, 2005. 